Vol. 1, No. 1, 2020

\author{
Anna Sotnikova ${ }^{1}$, Angela Francke ${ }^{2}$ \\ 1. Lviv Polytechnic National University \\ Bandery Str. 12, Lviv, Ukraine, 79000 \\ 2. Technische Universität Dresden \\ Hettnerstraße 1, 01069 Dresden, Germany \\ (C) Sotnikova A., Francke A., 2020 \\ https://doi.org/10.23939/tt2020.01.073
}

\title{
PEDESTRIAN AND CYCLIST FLOWS INTERACTION IN THE URBAN STREET AND ROAD NETWORK
}

\begin{abstract}
Summary. Due to the active popularization of sustainable urban mobility principles, there is an increase in the share of bicycle traffic in the overall modal split. The pedestrians are getting used to the fact that the cyclist is a full member of the traffic and has his/her own separate space. The concequence of this is cyclist and pedestrian flows conflicts.

The article analyses the results of field research of cycling and pedestrian traffic volume. The permissible number of conflicts between them is defined, which makes it possible to understand the principles of combination or separation of flows in space. Based on the results obtained, recommendations for the design and arrangement of cycling and pedestrian infrastructure are provided.

Key words: sustainable urban mobility, cycling, cycling infrastructure, cyclist flows, pedestrian flows.
\end{abstract}

\section{INTRODUCTION}

Recently, urban development design has been expanding on the principles of sustainable urban mobility. In line with these principles, research and planning of transportation systems should focus on walking and cycling. That is, urban infrastructure must, first and foremost, provide comfortable movement for these modes.

Bicycle is considered one of the most sustainable modes of transport in the urban transportation system. Professional literature assesses its impact on almost all spheres of life: environmental, social, economic, mobility, etc.

In Ukraine, separated cycling infrastructure still contains some novelty and is not perceived accordingly. Therefore, many pedestrians walk along the bike paths, ignoring the discomfort for cyclists. This is partly due to the lack of knowledge of pedestrians in the field of cycling and the lack of perfect normative regulation.

\section{RESEARCH STATEMENT}

In scientific works, much attention is paid to the study of the interaction of cyclist flows with motorized transport, as it is accompanied by considerable danger. However, no aspects of pedestrian interaction are rated. Often, it is mistakenly believed that joint or adjacent cyclist and pedestrian traffic can be quite safe.

Taking this into consideretion, the following hypotheses have been made: with pedestrian traffic volume growth, the number of violations increases; with the cyclist traffic volume growth, the number of violations decreases. 
On this basis, the purpose of this scientific study is to determine the boundary conditions under which pedestrians and cyclists may move adjacent to each other.

\section{PEDESTRIAN AND CYCLIST FLOWS INTERACTION IN THE URBAN STREET AND ROAD NETWORK}

Among the different ways of organizing cycling, the bike path is chosen the most often. However, its construction is the most difficult because it requires a lot of space and financial costs. It is most appropriate to design bike paths where another type of infrastructure is dangerous or impossible. This may be due to the high speed and / or volume of motorized transport. Although there are some drawbacks. While equipping a separate path for cycling, especially significantly remote or closed by various obstacles from the roadway, drivers do not expect the cyclist to appear at the intersection, which considerably increases the possibility of a traffic accident. In [8] it is stated that the cycle path is the best kind of infrastructure in long straight sections with a small number of intersections.

The authors [5] and the standard [13] have determined that in Ukraine bike paths should be equipped with cycling traffic volume of more than 50 bicycles / h, and the number of lanes should be calculated based on the capacity of $300 \mathrm{bicycles} / \mathrm{h} / \mathrm{lane}[13,15]$. According to other source, one or two lanes are sufficient [9].

In addition, bike paths and lanes should be different in colour and texture from other street or road elements. In Ukraine, they are marked with red [12]. Although colour marking is only required at intersections with other traffic flows.

Walking is a natural and basic form of human movement, and one of the basic aspects of personal freedom, so in some countries it is even regulated and protected by law $[2,6]$.

Despite the pedestrian traffic unpredictability, it can be classified as [14]:

- short- and long-term;

- mass and single;

- free and limited;

- agreed and disagreed;

- promiscuous (non-directional) and streaming (directional);

Considering the conditions that cause pedestrian movement (functional specificity), it can be divided into the following types [14]:

- organized mass movement - it is powerful, rarely repeated, lasts a long time (demonstrations, tips, etc.);

- impulse movement - repeated periodically, is fast enough and multi-channel (streams of people going to work / study in the morning);

- walking - its main purpose is the process of movement itself, not reaching the destination, is slower than the previous, more promiscuous.

Various types of infrastructure are used to make walking process comfortable: sidewalks, paths, trails, residential and pedestrian streets, alleys, shared space streets, colonnades, arcades, etc. [11, 13].

When designing pedestrian paths, it should be considered that this space will be used multifunctionally: movement, communication, rest. Also people with different physical abilities will use that infrastructure [14].

The basis for the pedestrian infrastructure arrangement is the ability to make it fully usable by lowmobility groups of the population [4].

The most common type of pedestrian infrastructure in Ukraine is the sidewalk. According to [13], it is an area designed for unobstructed movement along the street. Though it is forbidden to install various barriers on the pedestrian sidewalk (lighting supports, temporary structures, road fences, advertising constructions, etc.), obstacles are often encountered on the pedestrian way [13]. The inconvenience can be caused by insufficient width of the sidewalk, condition of its covering, excessive traffic volume as well, etc. [11]. 
For comfortable movement, considering pedestrian traffic volume, sidewalk width is calculated by the formula $[11,12]$ :

$$
B_{\text {sw }}=\frac{b_{p} \cdot N_{\text {ped }}}{P_{\text {ped }}}+a+b
$$

where $b_{p}$ - width of pedestrian lane for sidewalk, $\mathrm{m} ; N_{p e d}$ - pedestrian traffic volume in one direction, ped. / h; Pped - capacity of one sidewalk lane, ped. / h; $a$-additional sidewalk lane: $0.5 \mathrm{~m}$ - if sidewalk is adjacent directly to the lawn and $1.2 \mathrm{~m}$ - if there are some lighting masts or contact network supports; $b-$ safety lane: taken $0.6 \mathrm{~m}$ towards the roadway or bike path (lane) and $0.3 \mathrm{~m}$ - towards the building (in the presence of green protective plantations is not taken into account).

In $[7,11]$ the volume of the pedestrian flow is described as such equation:

$$
N=\frac{Q}{t}
$$

where $N$ - pedestrian traffic volume, ped./h; $Q$ - the number of people crossing the pedestrian crosssection, persons; $t$ - duration of the survey, h.

An indicator that is also used in the calculations is the specific volume of the pedestrian flow [11]:

$$
n=\frac{N \cdot b_{p}}{b}
$$

where $b_{p}$ - total width of the pedestrian path, $\mathrm{m} ; b$ - width of one lane for pedestrians, $\mathrm{m}$.

The width of one lane of pedestrian traffic is taken $0.75 \mathrm{~m}$ [13].

Design of a separate space for pedestrians and cyclists can solve the problem of conflict between these groups even before it arises. However, not always the road-street network meets all the parameters for their physical separation. In addition, sometimes combining pedestrian and cyclist flows can even have a positive effect.

In [8], the author states that pedestrian traffic areas should ensure pedestrians unhampered movement and staying on them. Cycling can cause some inconvenience, and if these areas are located along the way of urban cycling routes, detours are long and / or dangerous, so cycling may be permitted. Proceeding from this, the prohibition of cycling in pedestrian zones is possible, if there are other convenient cycling routes nearby, in the presence of intensive trade and a considerable density of pedestrians in the street. In such cases, the cyclists should dismount from their bicycles.

At the same time, the authors $[1,3]$ note that cyclist and pedestrian traffic are well combined in one space, since the speed difference is insignificant. Therefore, cycling should be allowed in all areas where motorized traffic is prohibited. The advantages of this solution are: increased cycling accessibility to more destinations (integrity requirement), avoidance of detours (straightness requirement).

According to [13], a common bicycle-pedestrian path can be used in the arterial streets of both continuous and regulated traffic, as well as in pedestrian streets. The limits of possibility of the adjacent bicycle-pedestrian movement introduction are shown in Fig. 1.

However, the joint movement of pedestrians and cyclists should not be used for such criteria [8]:

- intensive trade in the street;

- the high volume of low-mobility groups of the population as well as children;

- transit of urban cycling routes;

- a steep descent (>3\%) as the speed of cyclists significantly increases in such areas;

- short distance between the sidewalk (at its minimum width) and the building;

- a significant number of adjacent roads and exits from surrounding areas;

- sidewalks are used for waiting by public transport passengers (in the absence of equipped stops);

- exceeding the acceptable intensity limit for cyclists and pedestrians in accordance with Fig. 1. 


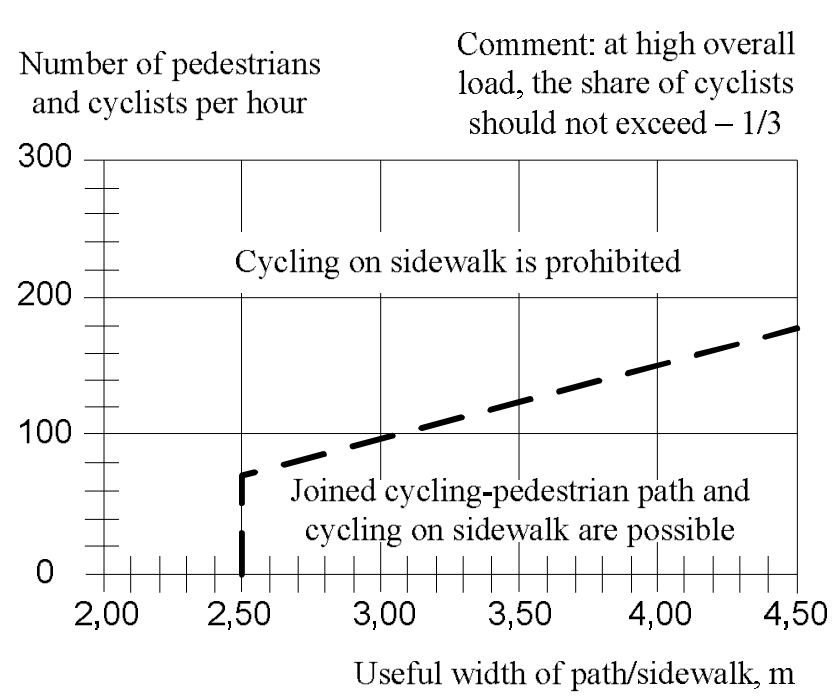

Fig. 1. Aplication limits of a shared bicycle-pedestrian path according to the number of pedestrians and cyclists and the width of the path/sidewalk [8]

The total path width should be at least $2.5 \mathrm{~m}$ with a small total intensity of cyclists and pedestrians [8].

Thus, in general, the combination of cyclist and pedestrian traffic is possible, but it is necessary to use delimitation at a considerable total intensity of these flows.

The standard [13] stipulates that the width of the separating lane between pedestrian and bike paths in all categories of city streets should be $0.25 \mathrm{~m}$, and [8] states that the minimum width should be $0.3 \mathrm{~m}$ and explains the other additional features that the separating lane of cycling and pedestrian flows should have:

- a clear structure that can be tactfully distinguished (for example, tactile tile, curb, row of pavers, change of coverage) to prevent blind pedestrians from getting the bike path;

- contrast (highlighting by colour, hue, reflective paint / plastic) for a clear visual distinction;

- the coating should allow easy accessibility and exclude stumbling.

In order to find out the principles of cyclist and pedestrian flows interaction, a methodology of field survey has been developed. The proposed hypothesis is based on the existence of violations of the rules by pedestrians, depending on the volume of pedestrians and cyclists traffic and the width of the pedestrian path. Violation implies the movement of a pedestrian by a bike path.

During the field research, the following indicators were recorded in the appropriate form: number of pedestrians, number of cyclists, number of pedestrian violations, width of pedestrian path / sidewalk.

In order the data obtained from all points of the local survey have the same meaning, the specific volume of pedestrians according to formula (3) is calculated, taking into account the width of the sidewalk.

\section{RESEARCH RESULTS AND PERSPECTIVES}

Eight points of survey were selected to investigate the cyclist and pedestrian flows interaction in Lviv, which according to the standard [9], by population, refers to large cities.

The obligatory conditions for the locations selection were:

- the bike path should be adjacent to the sidewalk, without separating lane;

- the accountant should not stay on the sidewalk or bike path so as not to obstruct the process of movement;

- there must be no obstacles near the cross section (within $10 \mathrm{~m}$ before and after it) that would encourage pedestrians to move on the bike path (supports, public transport stops, small architectural forms, etc.);

- those road users who crossed the cross-section of the researched area were recorded. 
Field studies were conducted on such streets:

1. Lypynskoho Str.;

2. Chornovola Ave.;

3. Chervonoyi Kalyny Ave;

4. Svobody Ave.; (next to the Solomiya Krushelnytska Lviv National Academic Theatre of Opera and Ballet);

5. Horodotska Str;

6. Naukova Str.;

7. Stusa Str;

8. Mytropolyta Andreya Str.

The research locations on the city map of Lviv are shown in Fig. 2. The item numbers correspond to the list above.

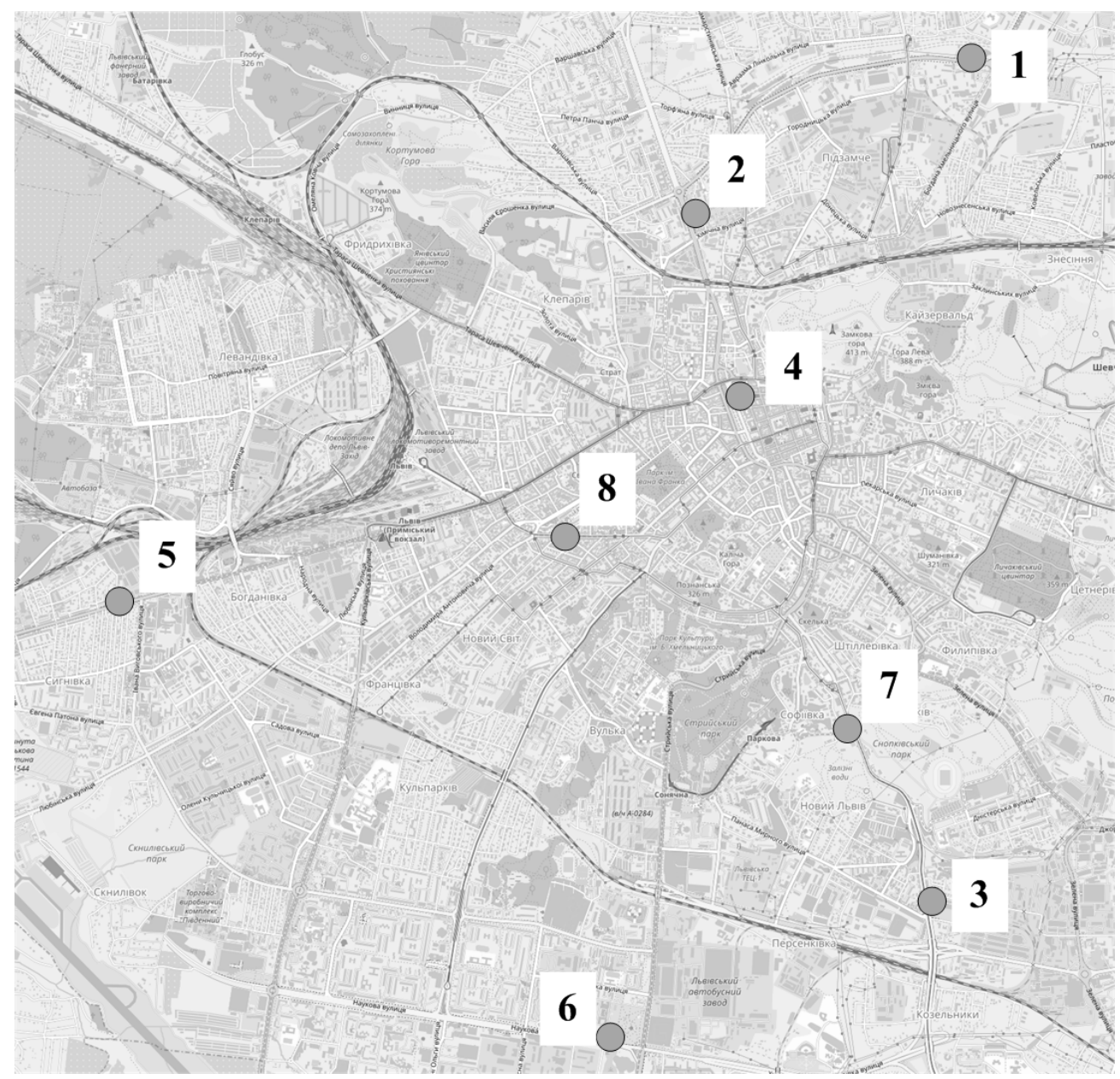

Fig. 2. The research points in Lviv city

The width of the sidewalk was measured at each location for further reduction of actual pedestrian traffic volume to the specific.

Based on the results of field survey, an appropriate database was formed. For the peak period the data are put into Table 1, and for the inter-peak period the data are put into Table 2.

According to the data obtained (for peak and inter-peak periods), trend lines were constructed for the specific pedestrians traffic volume (per one lane) and the volume of cyclists traffic with a common variable - the number of violations. The obtained dependences are described by second-order polynomial functions (formula 4 - formula 7) (Fig. 3 for the peak period, Fig. 4 - inter-peak period). 
Table 1

Results of field studies of pedestrian and bicycle traffic during the peak period

\begin{tabular}{|c|c|c|c|c|c|}
\hline Study location ID & $\begin{array}{c}\text { Pedestrians, } \\
\text { ped. / }\end{array}$ & $\begin{array}{c}\text { Pedestrians per } \\
\text { lane, ped. / / / ane }\end{array}$ & $\begin{array}{c}\text { Number of } \\
\text { violations, ped. / }\end{array}$ & Cyclists, cycl. / h & $\begin{array}{c}\text { Sidewalk } \\
\text { width, } \mathrm{m}\end{array}$ \\
\hline 1 & 132 & 66 & 48 & 26 & 1.5 \\
\hline 1 & 126 & 63 & 43 & 23 & 1.5 \\
\hline 1 & 117 & 59 & 37 & 29 & 1.5 \\
\hline 2 & 236 & 66 & 21 & 34 & 2.7 \\
\hline 2 & 201 & 56 & 31 & 27 & 2.7 \\
\hline 2 & 213 & 59 & 18 & 31 & 2.7 \\
\hline 3 & 138 & 69 & 40 & 6 & 1.5 \\
\hline 3 & 123 & 62 & 33 & 9 & 1.5 \\
\hline 3 & 140 & 70 & 45 & 3 & 1.5 \\
\hline 4 & 116 & 26 & 32 & 8 & 3.4 \\
\hline 4 & 156 & 34 & 48 & 11 & 3.4 \\
\hline 4 & 137 & 30 & 43 & 6 & 3.4 \\
\hline 5 & 88 & 28 & 30 & 4 & 2.4 \\
\hline 5 & 105 & 33 & 27 & 9 & 2.4 \\
\hline 5 & 97 & 30 & 31 & 8 & 2.4 \\
\hline 6 & 66 & 22 & 16 & 16 & 2.3 \\
\hline 6 & 71 & 23 & 22 & 21 & 2.3 \\
\hline 6 & 79 & 26 & 15 & 28 & 2.3 \\
\hline 7 & 78 & 31 & 50 & 8 & 1.9 \\
\hline 7 & 65 & 26 & 37 & 7 & 1.9 \\
\hline 7 & 70 & 28 & 46 & 7 & 1.9 \\
\hline 8 & 128 & 64 & 28 & 8 & 1.5 \\
\hline 8 & 106 & 53 & 23 & 11 & 1.5 \\
\hline 8 & 113 & 57 & 19 & 13 & 1.5 \\
\hline
\end{tabular}

Cyclists traffic volume, cycl. / $\mathrm{h}$
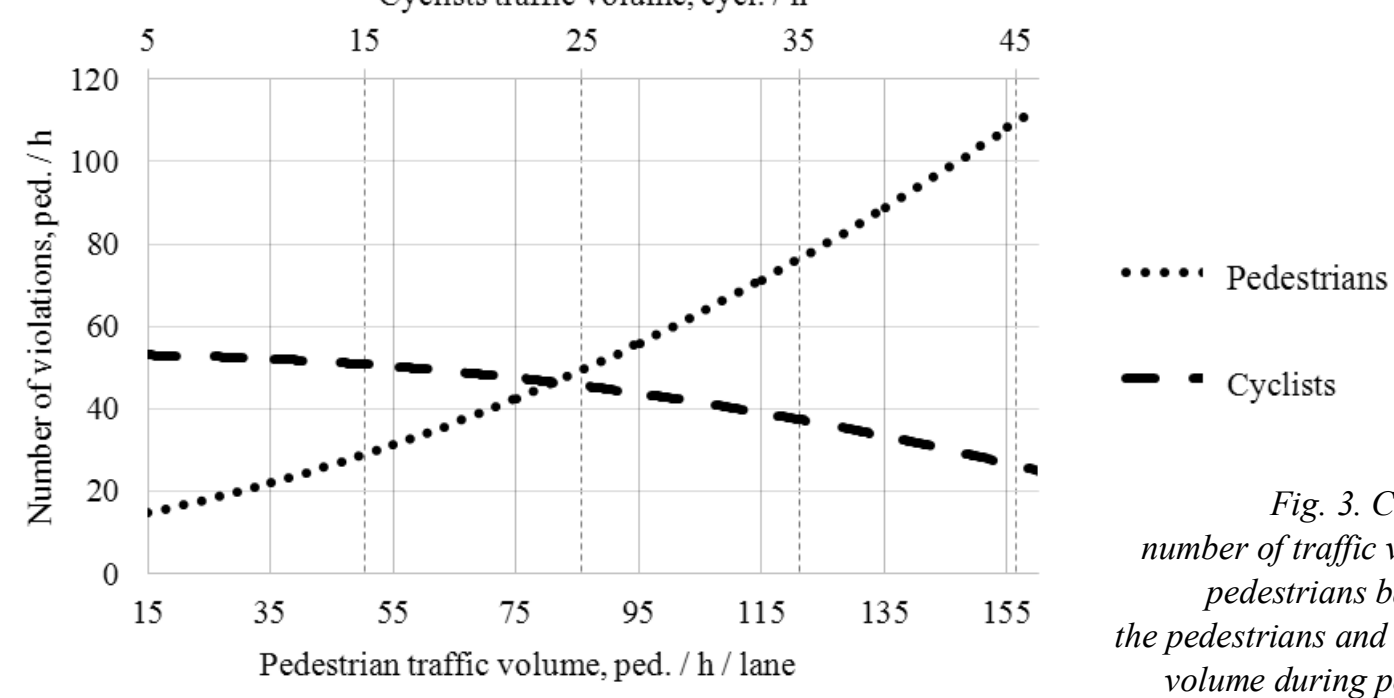

Fig. 3. Changing the number of traffic violations by pedestrians based on the pedestrians and cyclists traffic volume during peak period

For a clearer expression of the dependence of the abscissa axis in each graph are distributed from the smallest to the highest value of the indicator obtained during the studies. 
Table 2

\section{Results of field studies of pedestrian and bicycle traffic during the inter-peak period}

\begin{tabular}{|c|c|c|c|c|c|}
\hline Study location ID & $\begin{array}{c}\text { Pedestrians, } \\
\text { ped. / h }\end{array}$ & $\begin{array}{c}\text { Pedestrians per } \\
\text { lane, ped. / h / lane }\end{array}$ & $\begin{array}{c}\text { Number of } \\
\text { violations, ped. / h }\end{array}$ & Cyclists, cycl. / h & $\begin{array}{l}\text { Sidewalk } \\
\text { width, } \mathrm{m}\end{array}$ \\
\hline 1 & 132 & 66 & 48 & 26 & 1.5 \\
\hline 1 & 126 & 63 & 43 & 23 & 1.5 \\
\hline 1 & 117 & 59 & 37 & 29 & 1.5 \\
\hline 2 & 236 & 66 & 21 & 34 & 2.7 \\
\hline 2 & 201 & 56 & 31 & 27 & 2.7 \\
\hline 2 & 213 & 59 & 18 & 31 & 2.7 \\
\hline 3 & 138 & 69 & 40 & 6 & 1.5 \\
\hline 3 & 123 & 62 & 33 & 9 & 1.5 \\
\hline 3 & 140 & 70 & 45 & 3 & 1.5 \\
\hline 4 & 116 & 26 & 32 & 8 & 3.4 \\
\hline 4 & 156 & 34 & 48 & 11 & 3.4 \\
\hline 4 & 137 & 30 & 43 & 6 & 3.4 \\
\hline 5 & 88 & 28 & 30 & 4 & 2.4 \\
\hline 5 & 105 & 33 & 27 & 9 & 2.4 \\
\hline 5 & 97 & 30 & 31 & 8 & 2.4 \\
\hline 6 & 66 & 22 & 16 & 16 & 2.3 \\
\hline 6 & 71 & 23 & 22 & 21 & 2.3 \\
\hline 6 & 79 & 26 & 15 & 28 & 2.3 \\
\hline 7 & 78 & 31 & 50 & 8 & 1.9 \\
\hline 7 & 65 & 26 & 37 & 7 & 1.9 \\
\hline 7 & 70 & 28 & 46 & 7 & 1.9 \\
\hline 8 & 128 & 64 & 28 & 8 & 1.5 \\
\hline 8 & 106 & 53 & 23 & 11 & 1.5 \\
\hline 8 & 113 & 57 & 19 & 13 & 1.5 \\
\hline
\end{tabular}

Cyclists traffic volume, cycl. / h

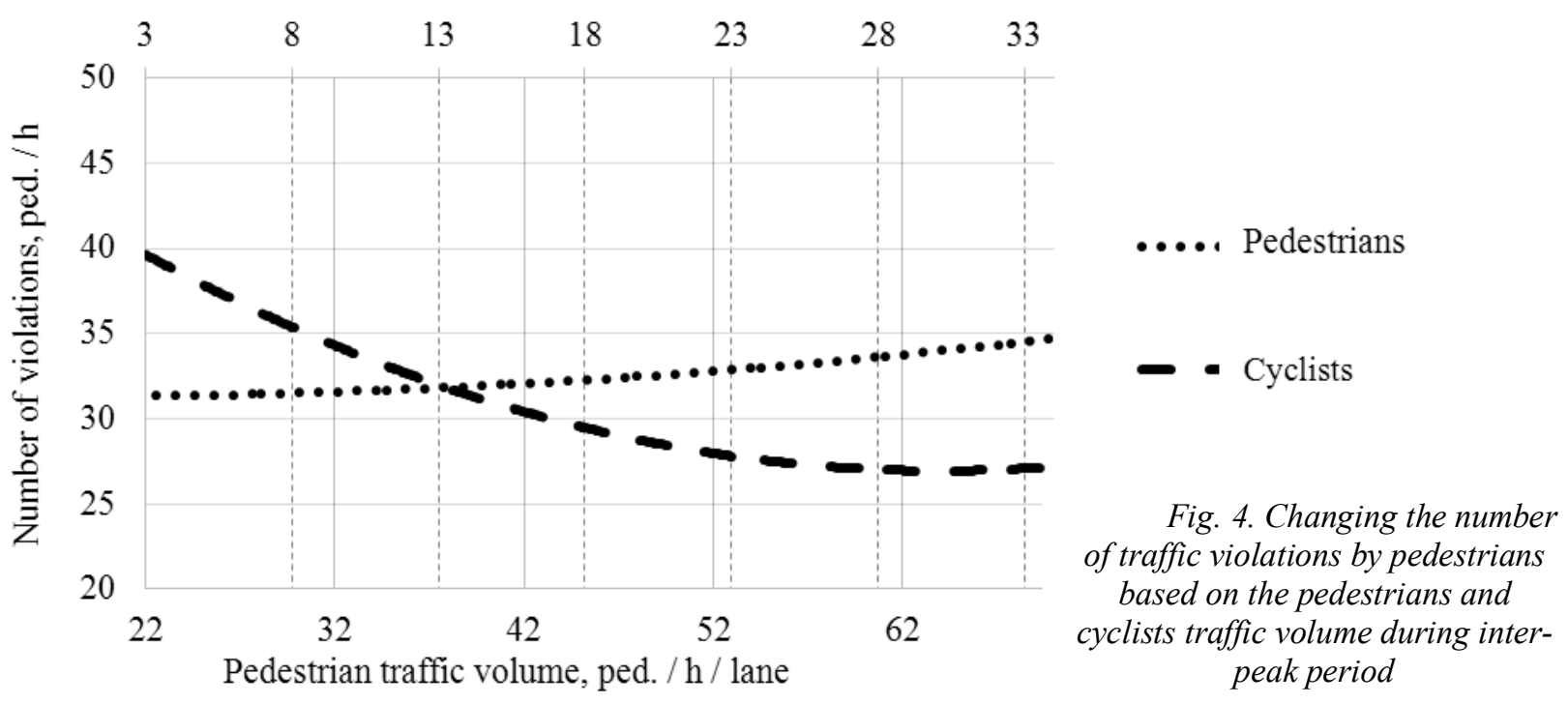

The obtained dependencies (Fig. 3 and Fig. 4) show that there is a direct dependence between the number of pedestrians and number of violations, and inversely dependence between the number of cyclists 
and number of violations. That is, with increase of pedestrian traffic volume on traffic lane, there is not enough space and they are forced to get on bike paths. At the same time, when the cyclists traffic volume increases, the number of violations decreases as pedestrians notice that the space of the bike path is not designed for them. According to the graphical method, the points of intersection of the trend lines for the peak period have the following values: $81 \mathrm{ped} . / \mathrm{h} / \mathrm{lane}, 24 \mathrm{cycl}$. / h, which corresponds to 46 traffic rules violations by pedestrians during the hour (ped./h). For the inter-peak period, these values are: $39 \mathrm{ped} . / \mathrm{h} / \mathrm{lane}, 14 \mathrm{cycl} . / \mathrm{h}$ and $33 \mathrm{ped} . / \mathrm{h}$ respectively. The values obtained demonstrate a relatively safe interaction limit between cyclist and pedestrian flows. For the inter-peak period, the result is lower as the traffic volume of both flows is lower. At the same time, with the number of pedestrians' growth, movement becomes more conjunct and people become more disciplined, that is, they begin to move psychologically, forming groups. This phenomenon is described by the so-called "crowd behaviour".

The dependence of the violations number of on the specific pedestrian traffic volume in the peak period is described by this function:

$$
y_{\text {ped.peak }}=0,0026 x^{2}+0,2325 x+10,793, R^{2}=0,8609
$$

where $x$-pedestrian traffic volume, ped. / h / lane, $y$ - number of violations, ped. / h.

The function of the dependence of the number of violations on the bicycle traffic volume for the same period looks like this:

$$
y_{\text {cycl.peak }}=-0.0149 z^{2}+0.0751 z+53.004, R^{2}=0.8086
$$

where $z$ - bicycle traffic volume, cycl. / h.

For the inter-peak period, the dependence of the number of violations on the specific pedestrian traffic volume is:

$$
y_{\text {ped.i- } \text { peak }}=0.0012 x^{2}-0.0411 x+31.657, R^{2}=0.8012
$$

And the dependence of the number of violations on the bicycle traffic volume is:

$$
y_{\text {cycl. } i-\text { peak }}=0.0173 z^{2}-1.0413 z+42.609, R^{2}=0.8497
$$

According to the practice of road-street network planning, providing comfortable traffic conditions for all road users during peak periods, other period of the day will also be convenient. Therefore, further recommendations are based on the data in Table 1 and on Fig. 3.

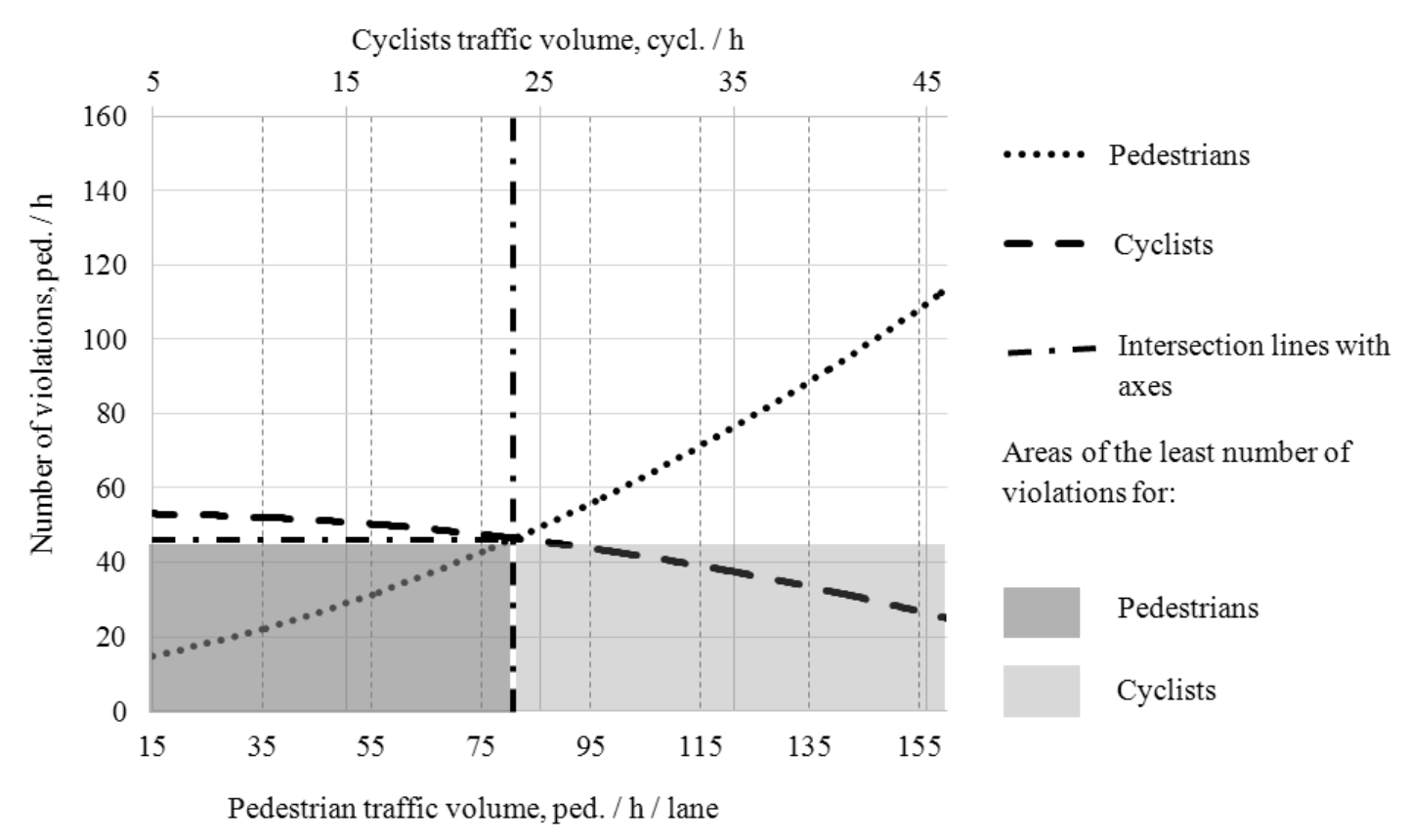

Fig. 5. Areas of the least number of violations 
The graph of the dependence of the number of violations on the pedestrians and cyclists traffic volumes (Fig. 3) shows the line of intersection of the optimal point with the coordinate axes. It reflects those values where, taking into account the traffic volumes of both flows, there are the fewest violations. That is, the allowable value of this indicator is $46 \mathrm{ped} . / \mathrm{h}$. Therefore, less than the permissible number of violations occurs at a specific pedestrian traffic volume of up to $81 \mathrm{ped} . / \mathrm{h} / \mathrm{lane}$ and at a bicycle traffic volume of more than $24 \mathrm{cycl} . / \mathrm{h}$. The obtained zones are shown in Fig. 5. However, the boundaries do not interact. Therefore, in order to determine the optimal value range for which pedestrians' and cyclists' infrastructure can be designed in conjunction, it is necessary to start from the intersection line with the abscissa axes in two directions (Fig. 6). This requires additional research and a larger sample of experimental data.

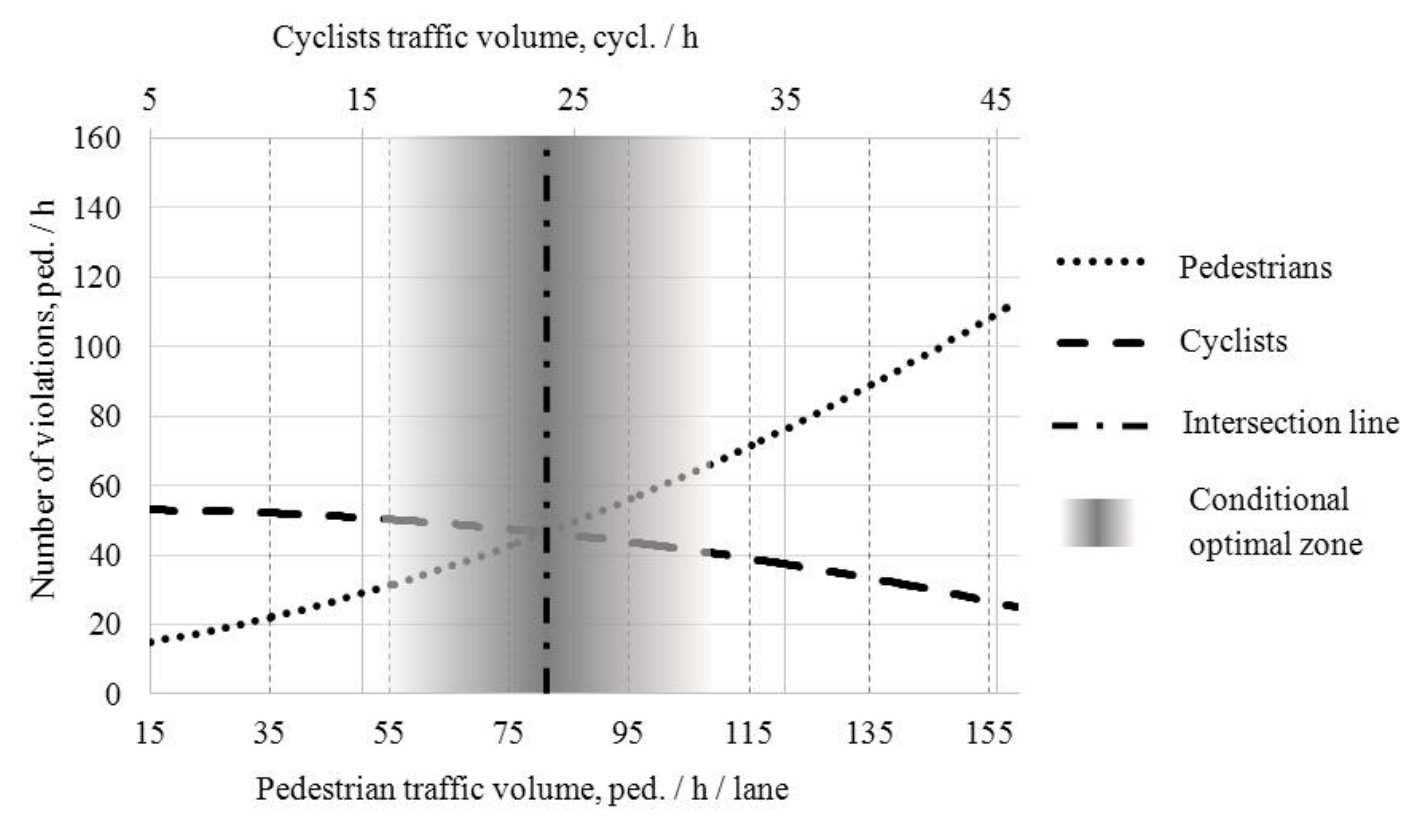

Fig. 6. Conditional optimal zone

\section{CONCLUSIONS}

According to the research, it is determined that the cyclist and pedestrian flows interaction is accompanied by a certain number of conflicts, the permissible number of which is 46 ped. / h. It has also been found that adjacent movement of pedestrians and cyclists can only happen within a certain traffic range. For pedestrians this value is in the range of up to $81 \mathrm{ped}$. / h / lane, and for cyclists $-24 \mathrm{cycl}$. / h.

Summarizing the above, the following recommendations have been formulated for the design and reconstruction of bike paths adjacent to pedestrian ones:

- the designed width of the sidewalk / pedestrian path should be calculated according to the volume of pedestrian traffic;

- the width of the sidewalk in the area where many violations are observed should be increased during the reconstruction;

- beyond the possible adjacent movement of pedestrians and cyclists between the sidewalk and the bike path, it is necessary to design a dividing lane that is structurally separated (for example, a border with a lawn and greenery);

- in the absence of space for the dividing strip, the design of the cycle lane should be taken into consideration;

- adjacent cycle paths and sidewalks should be visually separated - by a border, a tactile tile, with different color and texture of the covering, as well as with a slight difference in height; 
- sufficient and understandable road marking and the installation of appropriate road signs are obligatory.

\section{References}

1. Félix, R., Moura, F., \& Clifton, K. J. (2017). Typologies of Urban Cyclists: Review of Market Segmentation Methods for Planning Practice. Transportation Research Record: Journal of the Transportation Research Board 2662(1), 125-133. (in English)

2. Highway Design Manual. Bikeway Planning And Design (2015). Sacramento, California: California Department Of Transportation (in English)

3. Hinweise zu Detektionstechnologien im Straßenverkehr. (2019). FGSV Verlag GmbH (in German)

4. Improvement of territories. (2011). DBN B.2.2-5:2011 from 1st September 2011. Kyiv: Minrehionbud Ukrainy (in Ukrainian)

5. Lytvynenko T. P, Hasenko L. V. (2016). Metodyka stvorennya veloinfrastruktury u velykykh i serednikh mistakh [Methods of creating bicycle infrastructure in large and medium-sized cities]. Informatsiyni tekhnolohiyi ta zemleustriy $v$ upravlinni terytorialnym rozvytkom: materialy Vseukrayinskoyi Internet-konferentsiyi - Information Technologies and Land Management in Territorial Development Management: Proceedings of the All-Ukrainian Internet Conference (pp. 280-282). Poltava: PoltNTU (in Ukrainian)

6. Mahato N. K., Klar A. \& Tiwari S. (2018). Particle methods for multi-group pedestrian flow. Applied Mathematical Modelling, Volume 53, 447-461. (in English)

7. Namiot D. Ye., Kupriyanovskiy V. P., Karasev O. I., Sinyagov S. A. \& Dobrynin A. P. (2016). Velosipedy v Umnom Gorode [Bicycles in Smart City]. International Journal of Open Information Technologies. Volume 10. 9-14 (in Russian)

8. Nedim Fazlic (2019). Deutsche Regelwerke und die Verkehrswende: Teil der Lösung oder Teil des Problems? [German regulations and the turnaround in traffic: part of the solution or part of the problem?]. Berlin: Fachgebiet Integrierte Verkehrsplanung (in German)

9. Planning and development of territories. (2019). DBN B.2.2-12:2019 from 1st October 2019. Kyiv: Minrehionbud Ukrainy (in Ukrainian)

10. Road marking. (2010). DSTU 2587:2010 from 27th December 2010. Kyiv: Derzhspozhivstandart Ukrainy (in Ukrainian)

11. Shaleen Miller \& Christopher Coutts (2018). A multiple case study of local \& creative financing of bicycle and pedestrian infrastructure. Case Studies on Transport Policy, Volume 6. 257-264 (in English)

12. Solodkiy A. I., Gorev A. E. \& Bondareva E. D. (2017). Transportnaya infrastruktura : uchebnik $i$ praktikum dlya akademicheskogo bakalavriata [Transport infrastructure: tutorial and practice book for academic undergraduate]. Moscow: Yurait Publishing House (in Russian)

13. Streets and roads of settlements. (2018). DBN V.2.3-5:2018 from 1st September 2018. Kyiv: Minrehionbud Ukrainy (in Ukrainian)

14. Teknomo, Kardi. (2016). Microscopic Pedestrian Flow Characteristics: Development of an Image Processing Data Collection and Simulation Model. Retrieved from: https://www.researchgate.net/publication/308834581 _Microscopic_Pedestrian_Flow_Characteristics_Development_of_an_Image_Processing_Data_Collection_and_ Simulation_Model (in English)

15. Vehicular roads. (2007). DBN V.2.3-4:2007 from 1st March 2007. Kyiv: Minrehionbud Ukrainy (in Ukrainian)

Received 28.02.2020; Accepted in revised form 24.03.2020. 